\title{
TINDAK TUTUR DIREKTIF DALAM KABA CINDUA MATO KARYA SYAMSUDDIN ST. RAJO ENDAH
}

\author{
Dhea Pebri Yolanda ${ }^{1^{*}}$, Rona Almos ${ }^{2}$, Reniwati ${ }^{3}$ \\ dheafebriyolanda6@gmail.com* \\ Fakultas Ilmu Budaya Universitas Andalas ${ }^{1,2,3}$
}

\begin{abstract}
ABSTRAK
Tulisan ini mendeskripsikan bentuk dan jenis tindak tutur direktif yang terdapat dalam Kaba Cindau Mato. Teori yang digunakan dalam penelitian ini adalah teori tindak tutur dan teori jenis-jenis tindak tutur. Selanjutnya, metode dan teknik yang digunakan dalam analisis data ialah metode padan translasional dengan menggunakan teknik dasar pilah unsur penentu. Berdasarkan hasil analisis data, ditemukan lima bentuk tindak tutur direktif, yaitu tindak tutur memberi perintah, tindak tutur nasihat, tindak tutur menyarankan, tindak tutur meminta, dan tindak tutur melarang. Dari kelima bentuk tindak tutur direktif tersebut ditemukan sebanyak delapan puluh enam tuturan direktif. Jenis tindak tutur yang ditemukan dalam Kaba Cindua Mato karya Syamsuddin St. Rajo Endah adalah jenis tindak tutur langsung, tindak tutur tidak langsung, tindak tutur literal, tindak tutur langsung literal, dan tindak tutur tidak langsung literal.
\end{abstract}

Kata kunci: Cindua Mato, Tindak Tutur, Direktif, Bentuk, Jenis.

\section{THE DIRECTIVE SPEECH IN KABA CINDUA MATO BY SYAMSUDDIN ST. RAJO ENDAH}

\begin{abstract}
This paper describes the forms and types of directive speech contained in Kaba Cindua Mato. The theory used is the theory of speech acts and the theory of the speech acts types. Furthermore, the methods and techniques used in data analysis are the translational equivalent method using the basic technique of sorting the determinants. Based on data analysis results, five forms of directive speech acts were found: the speech act giving orders, the speech act for advice, the speech act suggesting, the speech act asking, and the speech act forbidding. There were found as many as eightysix directive speech acts from the five forms of directive speech acts. Types of speech acts found in Kaba Cindua Mato by Syamsuddin St. Rajo Endah are a type of direct speech act, indirect speech act, literal speech act, literal direct speech act, and indirect literal speech act.
\end{abstract}

Keywords: Cindua Mato, Speech, Directives, Forms, Types

Jurnal Elektronik WACANA ETNIK - Vol 9 No 1 2020, (19-28) p ISSN 2089-8746, e ISSN 2302-7142

Submit: Februari 2020. Diterima: Maret 2020. Publikasi: April 2020. 


\section{PENGANTAR}

Kaba adalah salah satu karya sastra klasik Minangkabau yang berbentuk prosa. Kata kaba sendiri berasal dari bahasa Arab yaitu khabar, yang artinya pesan, kabar atau berita. Kata khabar berubah dalam ucapan Minangkabau menjadi kaba. Berdasarkan sastra tradisional Minangkabau, kaba kadangkala disebut curito, malah sering disebut dengan nama gabungan, yaitu kaba curito (Taufik, 2009: 118).

Kaba merupakan salah satu bentuk warisan budaya yang tumbuh dan berkembang di masyarakat Minangkabau. Pada awalnya kaba disampaikan secara lisan oleh tukang kaba. Proses penyampaian cerita kaba disebut dengan istilah bakaba. Navis (1984: 244) mengatakan bahwa media yang semula tukang kaba, beralih ke buku. Ini disebabkan oleh mesin cetak yang menggunakan huruf Latin muncul, sehingga transformasi bentuk lisan kaba ke dalam bentuk tulisan dilakukan.

Pada dasarnya, cerita kaba banyak mengandung nilai-nilai kehidupan, pendidikan, dan pengajaran baik untuk kaum muda maupun kaum tua. Kaba juga berisi tentang pergaulan, nasehat-nasehat, tanggungjawab, adat berumah tangga, serta persolan kehidupan sosial masyarakat Minangkabau secara umum, begitu juga dengan Kaba Cindua Mato karya Syamsuddin St. Rajo Endah ini. Kaba Cindua Mato karya Syamsuddin St. Rajo Endah inibanyak mengandung nilai-nilai sosial masyarakat Minangkabau. Nilai-nilai sosial tersebut dapat dilihat pada setiap tindak tutur yang dihasilkan oleh tokoh dalam cerita Kaba Cindua Mato. Tindak tutur adalah tindakan yang dilakukan melalui ujaran atau tuturan (Yule, 2009). Selain bertutur juga ada tindakan yang disampaikan oleh penutur kepada mitra tutur.

Menurut penelitian-penelitian sebelumnya, Kaba Cindua Mato adalah gambaran keseimbangan kehidupan masyarakat Minangkabau, di mana semua aturan adat dijalankan. Keseimbangan kehidupan masyarakat Minangkabau yang terdapat dalam Kaba Cindua Mato, tentunya tidak terlepas dari bagaimana masing-masing tokoh dalam berkomunikasi, bagaimana tuturan meminta tolong, memberi perintah dan memberi nasehat. Semua itu tentunya dilihat dari tindak tutur yang dihasilkan oleh masing-masing tokoh. Oleh karena itu, penelitian ini dilakukan untuk melihat tindak tutur yang ada di dalam Kaba Cindua Mato karya Syamsuddin St. Rajo Endah. Tindak tutur yang dibahas dalam penelitian ini adalah tindak tutur direktif.

\section{KERANGKA TEORI DAN METODE}

Salah satu kajian dalam pragmatik adalah tindak tutur. Chaer (2010: 50) berpendapat bahwa tindak tutur sebagai gejala individual yang bersifat psikologis dan keberlangsungannya ditentukan oleh kemampuan bahasa si penutur dalam menghadapi situasi tertentu. Tindak tutur ini lebih menekankan pada makna atau arti tindakan dalam suatu ujaran. Sehubung dengan itu, Yule (2009) berpendapat bahwa tindak tutur adalah tindakan yang dilakukan melalui ujaran atau tuturan. Menurut Searle (dalam Wijana, 1996 : 17) secara pragmatik, setidaknya- tidaknya terdapat tiga tindakan yang dapat diwujudkan seorang penutur. Pertama, tindak lokusi (locutinary act) adalah tindak tutur menyatakan sesuatu (the act of saying something). Kedua, tindak ilokusi (ilocutionary act) adalah tindak tutur agar 
orang lain dapat mengerjakan sesuatu (the act of doing something). Ketiga, tindak perlokusi (perlocutionary act) adalah efek tuturan (perlocutionary force).

Searle (dalam Leech, 1993: 164) mengatakan bahwa tindak tutur direktif ialah tindak tutur yang bertujuan menghasilkan suatu efek berupa tindakan yang dilakukan oleh mitra tutur atau petutur, misalnya memberi perintah, memohon, memberi nasihat, meminta, menyarankan, dan melarang. Berikut ini adalah uraian tentang bentuk-bentuk tindak tutur direktif menurut Searle.

Memberi perintah adalah menyuruh seseorang untuk melakukan sesuatu. Ketika seseorang bertutur atau memberi perintah, yang mendapatkan keuntungan adalah orang yang memberi perintah atau penutur. Menurut Noviatri (2011: 63) bahwa dalam bahasa Minangkabau dijumpai sebuah partikel yang dapat memarkahi keimperatifan kalimat yaitu, partikel -lah. Partikel ini mempunyai peranan dan pemakaian yang sangat produktif, sebab penutur bahasa Minangkabau senantiasa menambah partikel -lah dalam mengungkapkan kalimat yang menyatakan perintah. Partikel -lah cenderung berfungsi sebagai penghalus dan penegas kalimat perintah. Menurut Kridalaksana (2008: 174) partikel adalah kata yang biasanya tidak dapat diderivasikan atau diinfleksikan, yang mengandung makna gramatikal dan tidak mengandung makna leksikal.

Menurut Kamus Besar Bahasa Indonesia (KBBI) Online, nasihat adalah ajaran atau pelajaran yang baik; anjuran (petunjuk, peringatan, teguran) yang baik. Ketika tuturan memberi nasihat diucapkan oleh penutur, maka yang mendapat untung adalah mitra tuturnya, karena tuturan nasihat itu berisi ajaran atau anjuran yang baik untuk mitra tutur.

Menyarankan atau menganjurkan berarti memberi saran, anjuran, atau pendapat. Menurut Rahardi (2008: 114), secara struktural tuturan ini ditandai dengan penggunaan kata hendaknya dan sebaiknya. Ketika tindak tutur menyarankan diucapkan oleh penutur, maka baik penutur maupun mitra tutur tidak mendapatkan keuntungan dari tuturan tersebut, karena tindak tutur menyarankan hanyalah saran atau pendapat saja. Menuut Rahardi (2008: 79) meminta ditandai dengan kadar suruhan sangat halus dan disertai sikap penutur yang merendah. Kalimat ini ditandai dengan kata tolong, mohon, harap atau frasa lain yang bermakna meminta.

Melarang berarti tidak mengizinkan seseorang untuk melakukan sesuatu. Menurut Rahardi (2008: 109) kalimat larangan biasanya ditandai dengan kata jangan. Hal ini sejalan dengan pendapat Moussay, dalam bukunya yang berjudul Tata Bahasa Minangkabau (1998: 112) mengatakan bahwa melarang atau larang disebut juga dengan perintah negatif yang diungkapkan dengan kata jan, usah dan indak buliah.

Bertolak dari pengertian tindak tutur dari beberapa para ahli bahasa mengenai tiga jenis tindak tutur, yaitu lokusi, ilokusi, dan perlokusi. Menurut Wijana (1996: 31-35) membagi tindak tutur berdasarkan kesesuaian maksud pembicara dengan kata-kata yang menyusunnya, yang dimaksud di sini adalah tindak tutur literal dan non literal. Selain itu, juga terdapat berbagai macam tindak tutur lainnya yang timbul karena adanya persinggungan atau keterkaitan antara tindak tutur langsung dan tidak langsung dengan tindak tutur literal dan tidak literal.

Pada tahap penyediaan data, peneliti menggunakan metode simak atau penyimakan, di mana peneliti meyimak tuturan-tuturan yang terdapat pada Kaba Cindua Mato karya Syamsuddin St. Rajo Endah. Teknik dasar 
yang digunakan adalah teknik sadap, yaitu pelaksanaan metode simak dengan menyadap tuturan- tuturan tokoh yang ada dalam Kaba Cindua Mato. Karena sumber penelitian ini berupa tuturan tertulis, maka teknik sadap dilakukan dengan cara membaca Kaba Cindua Mato karya Syamsuddin St. Rajo Endah. Kemudian dilanjutkan dengan teknik simak bebas libat cakap (SBLC) dan teknik catat. Dalam penerapan teknik simak bebas libat cakap (SBLC), peneliti tidak terlibat dalam proses komunikasi untuk mendapatkan data penelitian, karena data yang dibutuhkan peneliti bersifat pustaka atau tertulis. Seiring dengan teknik ini, peneliti mencatat data yang berhubungan dengan tindak tutur direktif yang terdapat dalam Kaba Cindua Mato. Setelah data terkumpul, data dikelompokkan sesuai dengan bentuk dan jenis direktifnya.

Setelah data terkumpul dan dikelompokkan sesuai dengan bentuk direktifnya, kemudian peneliti menganalisis data tersebut dengan menggunakan metode padan. Metode padan adalah metode dengan alat penentu luar, terlepas, dan tidak menjadi bagian dari bahasa yang bersangkutan, (Sudaryanto,1993: 13). Metode padan yang digunakan adalah metode padan pragmatis, dan metode padan translasional. Metode padan pragmatis adalah metode padan yang alat penentunya adalah mitra wicara, (Sudaryanto, 1993: 13). Metode padan translasional digunakan untuk menterjemahkan tuturan direktif yang berbahasa Minangkabau ke dalam bahasa Indonesia. Metode padan diwujudkan dengan teknik dasar pilah unsur penentu (PUP). Masing-masing teknik dasar pilah unsur penentu pragmatis, dan pilah unsur penentu translasional. Hal ini dilakukan untuk mencari perbedaan masing- masing penggunaan tuturan.

\section{HASIL DAN PEMBAHASAN}

Noviatri (2011: 63) berpendapat bahwa dalam bahasa Minangkabau dijumpai sebuah partikel yang dapat memarkahi keimperatifan kalimat, yaitu partikel -lah. Partikel ini mempunyai peranan dan pemakaian yang sangat produktif, sebab penutur bahasa Minangkabau senantiasa menambahkan partikel ini dalam mengungkapkan kalimat yang menyatakan perintah yang cenderung berfungsi sebagai penghalus atau penegas perintah. Peneliti menemukan bentuk perintah dengan menggunakan partikel -lah dan partikel -kan. Selain itu, juga ditemukan bentuk memberi perintah tanpa pemarkah. Berikut bentuk tindak tutur direktif memberi perintah dengan pemarkah -lah, -kan dan tanpa pemarkah.

Mano kalian nan baduo, ambiaklah buah batang kalapo, batang kalapo Nyiua Gadiang, ambiak buahnyo nan mudo, karambia sadang sudu-suduan, usah pulo nan mudo bana.

'Wahai kalian berdua, ambillah buah batang kelapa, batang kelapa Nyiua Gadiang, ambil buahnya yang muda, jangan yang terlalu muda'

Tuturan di atas dituturkan oleh Bundo Kanduang kepada dua orang dubalangnya, yaitu si Salamat Panjang Gombak dan si Barakat. Berdasarkan mimpinya, Bundo Kanduang disuruh untuk meminum buah kelapa Nyiua Gadiang yang tumbuh tidak jauh dari Istana Pagaruyung. Buah kelapa Nyiua Gadiang dikenal sangat keramat dan dijaga oleh binatang-binatang yang berbisa. Tetapi karena Bundo Kanduang memiliki kekuatan supranatural, maka cukup dengan semburan air yang sudah dibacakan mantra, lalu semua binatang yang menunggu batang kelapa itu pergi. Tuturan ini termasuk ke dalam bentuk tindak tutur memberi perintah, yang ditandai dengan kata kerja ambiak (ambil) dan ditambah dengan partikel -lah menjadi kata ambiaklah pada kalimat “Ambiaklah buah batang kalapo”. 
Tindak tutur ini diucapkan penutur bermaksud memberi perintah lawan tutur untuk mengambil buah batang kelapa yang dimaksudkan. Penggunaan kata kerja ambiak dan ditambah dengan partikel -lah pada tuturan di atas berfungsi sebagai kalimat perintah yang ditegaskan dengan partikel -lah. Data di atas dikategorikan sebagai jenis tindak tutur langsung karena modus kalimat yang digunakan sesuai dengan maksudnya. Pada tuturan tersebut modus kalimat yang digunakan Bundo Kanduang adalah kalimat perintah, yang ditandai dengan kata kerja ambiaklah. Kalimat perintah ini digunakan untuk menyuruh dubalang-dubalang Bundo Kanduang mengambil buah kelapa Nyiua Gadiang.

Manolah kito nan laki-laki, sagalo dubalang jo pagawai, sarato kito nan banyak iko. Musuah nan hampia ka tibo lai, dari Ulak Sungai Ngiang, handak mambaleh kasam anaknyo, iyolah Rajo Imbang Jayo, mati tabunuah di Padang Gantiang. Kini bapaknyo datang manuntuik, bapak kanduangnyo Tiang Bungkuak, urang bagak kuaik kaba. Manolah sagalo dubalang, siapkan sagalo alaik parang, usah kito balalai-lalai, musuah nan sadang dijalan, kalilah parik dalam-dalam, tanam ranjau batuang barunciang, sadiokan tobak jo galewang, buek lubang nan dalam, tahan jo ranjau bilah barauik, sagalo anak-anak suruah manyisiah, baitu juo induak-induak, suruah manyisiah jauah-jauah, beko talendo kanai darainyo.

'Untuk kita yang laki-laki, semua dubagalang dan pegawai. Musuh kita hampir sampai dari Sungai Ngiang, mereka hendak membalas dendam anaknya, yaitu Raja Imbang Jayo yang mati terbunuh di Padang Gantiang. Sekarang ayahnya datang menuntut kematian anaknya, yaitu Tiang Bungkuak yang sangat berani dan kebal. Manalah semua dubalang, siapkan semua alat perang, jangan kita beralalai-lalai lagi, musuh dalam perjalanan, galilah parit dalam-dalam, tanam ranjau dari betung runcing, sediakan tombak. Suruh semua anak-anak dan para wanita untuk sembunyi.'

Tuturan di atas diucapkan oleh Cindua Mato kepada semua rakyat Pagaruyuang. Tiang Bungkuak menuntut kematian anaknya, yaitu Imbang Jayo ke Pagaruyuang. Ia dan rakyatnya menyerang Pagaruyuang untuk membalaskan dendam anaknya, yaitu Imbang Jayo. Karena kedatangannya hampir sampai, Cindua Mato memberi perintah kepada rakyat Pagaruyuang untuk bersiap-siap melawan rakyat Tiang Bungkuak.

Tuturan ini termasuk ke dalam bentuk tindak tutur memberi perintah, yang ditandai dengan tuturan "Siapkan sagalo alaik parang, usah kito balalai-lalai, musuah nan sadang dijalan, kalilah parik dalam-dalam, tanam ranjau batuang barunciang, sadiokan tobak jo galewang, buek lubang nan dalam, tahan jo ranjau bilah barauik, sagalo anak-anak suruah manyisiah, baitu juo induak- induak, suruah manyisiah jauah-jauah, beko talendo kanai darainyo." Tindak tutur ini diucapkan penutur bermaksud memberi perintah lawan tutur untuk menyiapkan semua alat perang, dan membuat beberapa perangkap untuk rakyat Tiang Bungkuak. Data tersebut dikategorikan sebagai jenis tindak tutur langsung karena modus kalimat yang digunakan sesuai dengan maksudnya. Pada tuturan tersebut Cindua Mato menggunakan kalimat perintah kepada rakyatnya, agar menyiapkan alat perang, membuat ranjau sebagai perangkap untuk rakyat Tiang Bungkuak, dan menyuruh semua anak-anak dan para perempuan untuk sembunyi.

Di sisi lain, tindak tutur memberi perintah secara lisan ditandai dengan sufiks -an. Berhubung data tuturan pada peneltian ini bersifat tertulis, maka tindak tutur memberi perintah cenderung menggunakan partikel -kan sebagai penegas kalimat perintah. Penggunaan partikel -kan berada sesudah kata kerja dasar.

Lorong kapado Cindua Mato, ayam tangkeh tangah medan, acang-acang dalam nagari, limpapeh rumah nan gadang. Tambahan pulo nak kanduang, bisiakkan ka Datuak Bandaharo, maambiak Cindua Mato ka minantu. Kalau tak suko Datuak Bandaharo, kito nan tak malu bana, urang nan tidak mandangakan. Barisuak pagi kalian pai, bao si Barakat jo si Baruliah, batigo jo si Tambahi.

Jurnal Elektronik WACANA ETNIK - Vol 9 No 1 2020, (19 - 28) p ISSN 2089-8746, e ISSN 2302-7142 
'Cindua Mato adalah anak yang tangkas. Bisikkan pada Datuak Bandaharo untuk menjadikan Cindua Mato sebagai menantunya. Jika Datuak Bandaharo tidak suka, kita tidak akan dibuat malu, karna tidak ada yang mendengarnya. Besok pagi kalian pergi, bawa Barakat dan Baruliah, serta Tambahi.'

Tuturan di atas dituturkan oleh Bundo Kanduang kepada anaknya Sutan Rumanduang (Dang Tuangku). Bundo Kanduang memberikan izin kepada Cindua Mato untuk pergi ke Sungai Tarab mengikuti acara yang diadakan oleh Datuak Bandaharo sekaligus mengajak Dang Tuangku ikut bersama dengannya. Kemudian, Bundo Kanduang mengatakan kepada Dang Tuangku untuk membisikkan kepada Datuak Bandaharo agar menjadikan Cindua Mato sebagai menantunya, serta membawa ketiga dubalangnya.

Tuturan ini termasuk ke dalam bentuk tindak tutur memberi perintah, yang ditandai dengan kata bisiakkan pada kalimat "Bisiakkan ka Datuak Bandaharo", dan kata bao pada kalimat "Bao si Barakat jo si Baruliah". Tindak tutur ini diucapkan penutur bermaksud memberi perintah lawan tutur untuk membisikkan sesuatu yang diamanatkan kepada mitra tutur. Data di atas dikategorikan sebagai jenis tindak tutur langsung karena modus kalimat yang digunakan sesuai dengan maksudnya. Pada tuturan tersebut Bundo Kanduang menggunakan kalimat perintah kepada Dang Tuangku untuk membisikkan kepada Datuak Bandaharo mengambil Cindua Mato sebagai menantunya.

Tindak tutur memberi perintah dengan tanpa pemarkah, ditandai dengan penggunaan kata kerja dasar sebagai penentu kalimat memberi perintah pada tuturan.

Mano ang si Barakat, japuik Juaro Medan Labiah, bao ayam sikua, sarato taji sabarumbuang, sarato banang satintiangan, japuik tabao kini juo.

'Wahai kamu si Barakat, jemput Juaro Medan Labiah, bawa seekor ayam, serta benang, jemput sekarang juga.'

Tuturan diatas diucapkan oleh Bundo Kanduang kepada dubalangnya, yaitu Barakat. Sebelum Cindua Mato dan Sutan Rumanduang pergi ke perhelatan Datuak Bandaharo, Bundo Kanduang memberi perintah Barakat untuk pergi menjemput Juaro Medan Labiah dengan membawa seekor ayam dan benang.

Tuturan ini termasuk ke dalam bentuk tindak tutur memberi perintah, yang ditandai dengan kata kerja dasar japuik pada kalimat "Japuik Juaro Medan Labiah", dan kata bao pada kalimat "Bao ayam sikua". Tindak tutur ini diucapkan penutur bermaksud memberi perintah lawan tutur untuk menjemput seseorang dan membawa sesuatu yang diperintahkan. Data tersebut dikategorikan sebagai jenis tindak tutur langsung karena modus kalimat yang digunakan sesuai dengan maksudnya. Pada tuturan tersebut Bundo Kanduang menggunakan kalimat perintah kepada dubalangnya untuk pergi menjemput Juaro Medan Labiah, serta membawa seekor ayam.

Cari si Buyuang Cindua Mato, bao kamari kini juo, disuruah japuik si Binuang.

'Cari si Buyung Cindua Mato, bawa ke sini sekarang juga, disuruh unutuk menjemput si Binuang.'

Tuturan di atas diucapkan oleh Bundo Kanduang kepada Barakat, Baruliah dan Tambahi. Sebelumnya Bundo Kanduang memerintahkan ketiga dubalangnya itu untuk menangkap kerbau Binuang, tetapi mereka gagal. Lalu, 
Bundo Kanduang memerintahkan mereka untuk mencari Cindua Mato untuk ke istana, karena Bundo Kanduang ingin Cindua Mato untuk menangkap dan membawa kerbau Binuang.

Tindak tutur ini termasuk ke dalam bentuk tindak tutur memberi perintah, yang ditandai dengan kata kerja dasar cari pada kalimat “Cari si Buyuang Cindua Mato”. Tindak tutur ini diucapkan penutur bermaksud memberi perintah lawan tutur untuk mencari keberadaan Cindua Mato. Data di atas dikategorikan sebagai jenis tindak tutur langsung karena modus kalimat yang digunakan sesuai dengan maksudnya. Pada tuturan tersebut Bundo Kanduang menggunakan kalimat perintah kepada dubalangnya untuk mencari keberadaan Cindua Mato.

Manolah Datuak Manti Tuo, japuik Mangkudun di Sumaniak, Tuan Gadang di Batipuah, Tuan Indomo di Saruaso, Bandaharo di Sungai Tarab, katokan malah elok-elok, Puti Bungsu alah kamari, anak Tuanku Rajo Mudo, datang nan dari Ulak Sikalawi, kini barado di Padang Gantiang, di dalam Ustano Tuan Kadi, sabab tidak ka Pagaruyuang, sudah tasabuik sajak dahulu, Puti Bungsu dalam batunangan, tunangan Daulat Dang Tuangku, karano baliau balun kawin, raso malu kaduonyo, mamintak baliau ringan kaki datang jo si Bungsu, itulah sambah ka baliau.

'Manalah Datuak Manti Tuo, jemput Mangkudun di Smaniak, Tuan Gadang di Batipuah, Tuan Indomo di Saruaso, Bandaharo di Sungai Tarab, katakan baik-baik bahwasanya Puti Bungsu ada di sini, anak Tuanku Rajo Mudo, datang dari Ulak Sikalawi, sekarang berada di Padang Gantiang, di Istana Tuan Kadi. Sebab tidak ke Pagaruyuang, sudah tersebut sejak dahulu, Puti Bungsu sedang dalam bertunangan dengan Dang Tuangku, karena mereka belum menikah, malu rasanya mereka berdua, minta pada beliau untuk datang dengan suka hati.'

Tuturan di atas diucapkan oleh Tuan Kadi kepada Datuak Manti Tuo. Saat mengetahui Puti Bungsu datang, Tuan Kadi langsung memerintah Datuak Manti Tuo untuk menjemput Basa Ampek Balai untuk datang ke Istana Tuan Kadi di Padang Gantiang, karena Puti Bungsu sedang ada di sana.

Tuturan ini termasuk ke dalam bentuk tindak tutur memberi perintah, yang di tandai dengan kata japuik pada kalimat “Japuik Mangkudun di Sumaniak”. Tindak tutur ini diucapkan penutur kepada lawan tutur bermaksud memberi perintah lawan tutur untuk menjemput Basa Ampek Balai. Penentu maksud memberi perintah terdapat pada penggunaan kata kerja dasar japuik (jemput). Berdasarkan jenis tindak tutur, data (42) dikategorikan sebagai jenis tindak tutur langsung karena modus kalimat yang digunakan sesuai dengan maksudnya. Pada tuturan tersebut Tuan Kadi menggunakan kalimat perintah kepada Datuak Manti Tuo untuk menjemput Basa Ampek Balai.

Sababnyo anak Bundo jagokan, danga di anak kato hambo, simakkan bana elok-elok. Anak batambah gadang juo, mandeh baansua tuo juo, lurah dalam bukik lah tinggi, harilah patang nan di Bundo, anak nan tidak batunjuaki, dangakan bana Bundo curaikan, Bundo papakan. Adat limbago dalam nagari. Tambo Adat Minangkabau, sabarih bapantang lupo, satitiak nan tidak hilang. Nan tapakai di Alam nangko. Sajak salareh Batang Bangkaweh, saedaran Gunuang Marapi, ka duo Gunuang Singgalang, ka tigo Gunuang Talang, sampai ka Gunuang Pasaman, itu di bawah parentah anak, ganggam taguah pacik arek.

'Sebab anak ibu bangunkan, dengarkan kata ibu, simakkan baik-baik. Anak semakin bertambah besar, ibu berangsur tua, kamu yang tidak diajari, dengarkan dengan baik yang ibu katakan. Adat dalam negeri menurut Tambo Adat Minangkabau, sebaris tidak akan lupa, setitik yang tidak akan hilang. Mulai dari Batang Bangkaweh, saedaran Gunung Merapi, ke dua Gunung Singgalang, ketiga Gunung Talang, sampai ke Gunung Pasaman, itu semua berada di bawah perintahmu.'

Jurnal Elektronik WACANA ETNIK - Vol 9 No 1 2020, (19-28) p ISSN 2089-8746, e ISSN 2302-7142 
Tuturan di atas diucapkan oleh Bundo Kanduang kepada Dang Tuangku. Bundo Kanduang merasa dirinya sudah tua, akan tiba saatnya Bundo Kanduang akan digantikan oleh anaknya. Lalu, Bundo Kanduang memberikan nasehat kepada Dang Tuangku tentang batasan-batasan wilayah yang berada dibawah pimpinan Dang Tuangku kelak.

Tuturan ini termasuk ke dalam bentuk nasehat yang ditandai dengan tuturan "Anak batambah gadang juo, mandeh baansua tuo juo, lurah dalam bukik lah tinggi, harilah patang nan di Bundo, anak nan tidak batunjuaki”. Tindak tutur ini diucapkan penutur bermaksud menasehati dan memberi pengajaran kepada lawan tutur tentang batasan-batasan wilayah kekuasaannya. Data tersebut dikategorikan sebagai jenis tindak tutur tidak langsung literal karena kalimat yang disampaikan oleh Bundo Kanduang adalah kalimat berita, yaitu menyampaikan batasan-batasan wilayah yang menjadi wilayah pemerintahan Dang Tuangku. Tetapi, tuturan itu secara tidak langsung memberi perintah kepada Dang Tuangku untuk mendengarkan dengan baik-baik nasehat yang dituturkan oleh Bundo Kanduang.

Mano ang Buyuang Rumanduang, sarato Bujang Kacinduan, mamakai anak kaduonyo, sabalun hari tinggi bana, elok bajalan kini-kini.

'Wahai kamu Buyung Rumanduang dan Bujang Kacinduan, segeralah bersiap-siap sebelum hari petang, sebaiknya berangkat sekarang'.

Tuturan di atas dituturkan oleh Bundo Kanduang kepada Cindua Mato dan Dang Tuangku. Cindua Mato dan Dang Tuangku akan pergi ke acara yang diadakan oleh Datuak Bandaharo. Lalu, Bundo Kanduang memberi mereka saran agar sebaiknya berangkat lebih awal, karena tempat yang akan dituju itu jauh.

Tuturan ini termasuk ke dalam tindak tutur menyarakan, yang ditandai dengan kata elok pada kalimat "Elok bajalan kini-kini”. Tindak tutur ini diucapkan penutur bermaksud menyarankan lawan tutur untuk segera berangkat karena tempat yang dituju sangat jauh. Data di atas dikategorikan sebagai jenis tindak tutur langsung karena modus kalimat yang digunakan sesuai dengan maksudnya. Pada tuturan tersebut Bundo Kanduang menggunakan kalimat perintah kepada para Dang Tuangku dan Cindua Mato untuk segera bersiap-siap.

Meminta adalah berkata-kata supaya diberi atau mendapatkan sesuatu dari orang lain, Almos (2013, 31).

Ampun hambo Bundo Kanduang, ado takana pado hati, bari izin hambo bajalan, hambo ka pai ka Sungai Tarab, ka Galanggang Datuak Bandaharo, sadang mamacak galanggang, mancari minantu Tuan Titah, iyo si upiak si Lenggo Geni. Lah banyak urang nan datang, surang tidak nan manjadi, urang namuah awak anggan, awak namuah awak anggan, tak ubah kanai santuang palalai. Galanggang sangaik rami bana, dimano-mano urang datang, mukasuik hati nan kasanan, hambo bao ayam Kinantan, ayam batuah jo kiramaik, makannyo ditapak tangan, kalau minum diujuang kuku, pandai bakukuak di awang-awang.

'Ampun saya Bundo Kanduang, beri saya izin untuk pergi ke Sungai Tarab, ke acara Datuak Bandaharo yang sedang mencari menantu untuk anaknya Lenggo Geni. Sudah banyak yang datang, tapi satupun tidak didapat. Acaranya sangat ramai, banyak orang yang berdatangan. Maksud hati kesana untuk membawa ayam Kinantan yang keramat.'

Tuturan di atas dituturkan oleh Cindua Mato kepada Bundo Kanduang. Cindua Mato mendengar kabar bahwasanya Datuak Bandaharo sedang mengadakan acara di Sungai Tarab, sekaligus mencarikan suami untuk 
anaknya, yaitu Putri Lenggo Geni. Cindua Mato berniat untuk pergi ke galanggang (acara) yang diadakan oleh Datuak Bandaharo dengan membawa ayam Kinantan yang keramat.

Tuturan ini termasuk ke dalam bentuk tindak tutur meminta yang ditandai dengan tuturan "Bari izin hambo bajalan". Tindak tutur ini diucapkan penutur bermaksud meminta izin kepada lawan tutur untuk memberikan izin kepada penutur pergi ke acara tersebut. Data tersebut dikategorikan sebagai jenis tindak tutur langsung literal. Tuturan meminta disampaikan dengan modus kalimat berita. Cindua Mato menyampaikan kepada Bundo Kanduang tentang acara yang sedang diadakan oleh Datuak Bandaharo, dan ia meminta izin untuk pergi ke sana. Modus kalimat, maksud tuturan dan makna kata-kata yang menyusunnya sama.

Melarang adalah kebalikan dari memberi perintah. Jika memberi perintah untuk melakukan sesuatu, sedangkan melarang justru tidak boleh melakukan sesuatu. Menurut Moussay (1998: 12) melarang atau larang disebut juga dengan perintah negatif biasanya diungkapkan dengan kata jan, usah dan indak buliah.

Manolah kalian samuonyo, kalau baitu kato basamo, hambo tarimo jo suci hati, sudah adatjo biaso, gajah tadorong digadiangnyo, harimau talompek dek balangnyo. Kini baitu pintak hambo,usah kalian manyamun juo, nak sanang urang nan lalu, badoso kito pado Allah. Jikok kalian mungkia janji, dimakan kutuak Bundo Kanduang, iyo dimakan biso kawi.

'Wahai kalian semuanya, kalau begitu kesimpulannya, saya terima dengan hati suci. Sekarang saya minta, jangan kalian menyamun lagi, biar tenang orang yang lewat. Jika kalian mengingkari janji, maka akan terkena kutuk Bundo Kanduang.'

Tuturan di atas diucapkan oleh Cindua Mato kepada para penyamun. Karena ketangkasan Cindua Mato dalam melawan para penyamun, lalu para penyamun tersebut mengaku kalah kepada Cindua Mato. Semua penyamun tidak berani lagi kepada Cindua Mato. Karena para penyamun kalah, Cindua Mato melarang mereka untuk tidak merampas siapapun yang melewati Bukit Tambun Tulang, dan tidak membunuh mereka yang lewat.

Tuturan ini termasuk ke dalam bentuk tindak tutur melarang, yang ditandai dengan tuturan "Usah kalian manyamun juo". Kata yang menandai tuturan tersebut termasuk ke dalam tindak tutur melarang adalah pada kata usah. Tuturan pada data tersebut termasuk ke dalam jenis tindak tutur literal karena maksud tuturan sesuai dengan makna kata-kata yang menyusunnya. Cindua Mato melarang para penyamun untuk tidak menyamun lagi, karena itu adalah perbuatan dosa.

\section{PENUTUP}

Berdasarkan hasil analisis data dan pembahasan mengenai tindak tutur direktif dalam Kaba Cindua Mato karya Syamsuddin St. Rajo Endah, ditemukan 5 bentuk tindak tutur direktif, yaitu tindak tutur memberi perintah , tindak tutur nasihat, tindak tutur menyarankan, tindak tutur meminta, dan tindak tutur melarang. Dari kelima bentuk tindak tutur direktif tersebut ditemukan 84 tuturan direktif. Tuturan yang paling banyak digunakan adalah tuturan memberi perintah, dan tuturan yang paling sedikit adalah tuturan melarang.

Jenis tindak tutur yang ditemukan dalam Kaba Cindua Mato karya Syamsuddin St. Rajo Endah adalah jenis tindak tutur langsung, tindak tutur tidak langsung, tindak tutur literal, tindak tutur langsung literal, dan tindak tutur 
tidak langsung literal. Jenis tuturan yang paling banyak digunakan adalah tindak tutur langsung, dan jenis tindak tutur yang paling sedikit digunakan adalah jenis tindak tutur tidak langsung.

\section{REFERENSI}

Abdullah, Taufik. 2009. Beberapa Catatan Tentang Kaba Cindua Mato: Satu Contoh Sastera Tradisional Minangkabau, dalam Jurnal Terjemahan Alam dan Tamadun Melayu, 1. 117-137.

Almos, Rona. 2013. Realitas Ujaran Pantang Bahasa Minangkabau. Padang: PSIKM

Chaer, Abdul dan Leonie Agustina. Sosiolinguistik (Perkenalan Awal). 2010. Jakarta: PT. Rineka Cipta.

Dewi, Fitria, dkk. 2017. Kosakata Bahasa Minangkabau Yang Berpotensi Arkais Dalam Kaba Cindua Mato. Salingka, Volume 14 Nomor 2, hlm 99-110.

Endah, Syamsuddin St. Rajo. 1987. Cindua Mato. Bukittinggi: Pustaka Indonesia.

Ibrahim, Abd. Syukur. 1992. Kajian Tindak Tutur. Surabaya: Usaha Nasional.

Juita, Novia. 2016. Tindak Tutur Tokoh Dalam Kaba: Pencerminan Kearifan Dan Kesantunan Berbahasa Etnis Minangkabau dalam Humanus Vol. XV No.1 Tahun 2016. Padang: Lembaga Penelitian Universitas Negeri Padang.

Kridalaksana, Harimurti. 2008. Kamus Linguistik (Edisi Keempat). Jakarta: PT Gramedia Pustaka Utama.

Leech, Geoffrey. 1993. Prinsip-prinsip Pragmatik. Jakarta: Universitas Indonesia. Moussay, Gerard. 1998. Tata Bahasa Minangkabau. Jakarta: Kepustakaan Populer

Nadar, F.X. 2009. Pragmatik \& Penelitian Pragmatik. Yogyakarta: Graha Ilmu. Navis, A.A. 1984. Alam Terkembang Jadi Guru. Jakarta: Grafiti Pers.

Novalia, Rima. 2004. "Pergeseran Makna dalam Kaba Cindua Mato Terjemahan". (Skripsi). Padang: Universitas Andalas.

Noviatri. 2011. Kalimat Imperatif Bahasa Minangkabau. Padang: Minangkabau Press.

Rahardi, Kunjana. 2008. Pragmatik Kesantunan Imperatif Bahasa Indonesia. Jakarta: Erlangga.

Rizal, Kuyung. 2003. "Referensi dalam Kaba Cindua Mato". (Skripsi). Padang: Universitas Andalas.

Revita, Ike. 2013. Pragmatik (Kajian Tindak Tutur Permintaan Lintas Bahasa). FIB: Universitas Andalas

Sudaryanto. 1993. Metode dan Aneka Teknik Analisis Bahasa. Yogyakarta: Duta Wacana University Press.

Wijana, I Dewa Putu. 1996. Dasar-dasar Pragmatik. Yogyakarta: Andi Offset.

Yahya, Iwan Khairi. 2013. "Tindak Tutur Direktif Dalam Interaksi Belajar Mengajar Mata Pelajaran Bahasa dan Sastra Indonesia di SMA Negeri 1 Mlati, Sleman, Yogyakarta". (Skripsi). Yogyakarta: Universitas Negeri Y ogyakarta. http://eprints.uny.ac.id/08201244053(1). pdf/. Diunduh pada tanggal 21 Mei 2019.

Yule, George. 2009. Pragmatik. Yogyakarta: Pustaka Pelajar. 